DOI: $10.15193 /$ zntj/2017/110/172

\author{
MICHAŁ PAŁYS, ZDZISŁAW TARGOŃSKI, ELWIRA KOMOŃ-JANCZARA, \\ AGNIESZKA GLIBOWSKA
}

\title{
SELEKCJA NOWO WYIZOLOWANYCH SZCZEPÓW RHIZOPUS ORYZAE DO WYDAJNEJ PRODUKCJI KWASU L(+) MLEKOWEGO
}

\author{
Streszczenie
}

\begin{abstract}
Celem pracy była ocena zdolności nowo wyizolowanych szczepów z rodzaju Rhizopus do produkcji kwasu mlekowego. W przypadku 20 izolatów, spośród 40 przebadanych, w filtratach pohodowlanych stwierdzono znaczące stężenia kwasu mlekowego. Były to szczepy zaliczone do gatunku Rhizopus oryzae, podczas gdy pozostałe szczepy, w tym należące do gatunku Rhizopus stolonifer, tych uzdolnień nie przejawiały. Stężenia kwasu mlekowego w filtratach były zróżnicowane w zależności od użytego szczepu grzyba oraz rodzaju źródła węgla. Najwyższe stężenie kwasu mlekowego - 74,06 g/l oznaczono w filtracie pohodowlanym szczepu Rhizopus oryzae R-42, w podłożu zawierającym 100 g/l glukozy. Największą wydajność kwasu mlekowego wynoszącą 89,4 \% oraz produktywność - blisko 0,5 g/l/h uzyskano również po hodowli szczepu $R$. oryzae R-42 na podłożu zawierającym 50 g/l glukozy. Nieznacznie niższe wartości stwierdzono, gdy jako źródło węgla użyto mannozy lub fruktozy. Zdecydowanie niższe wartości otrzymano natomiast, gdy źródłem węgla była ksyloza lub skrobia. Spośród badanych szczepów tylko 6 było zdolnych do wzrostu i produkcji kwasu mlekowego w podłożu z sacharozą, Najlepszy szczep $R$. oryzae R83 charakteryzował się dużą wydajnością produkcji kwasu mlekowego wynoszącą blisko $90 \%$ na podłożu $\mathrm{z}$ dodatkiem $50 \mathrm{~g} / 1$ sacharozy. Wszystkie badane szczepy wytwarzały kwas L(+) mlekowy.
\end{abstract}

Słowa kluczowe: Rhizopus oryzae, kwas L(+) mlekowy, fermentacja, sacharydy

\section{Wprowadzenie}

Grzyby gatunku Rhizopus oryzae są zdolne do produkcji kwasu mlekowego i kwasu fumarowego [5]. Produktem ubocznym fermentacji jest etanol [8, 9]. Niekiedy kwasowi fumarowemu towarzyszy kwas mlekowy i odwrotnie. Dlatego poszukując

Dr inż. M. Pałys, Centralne Laboratorium Agroekologiczne, Uniwersytet Przyrodniczy w Lublinie, ul. B. Dobrzańskiego 3, 20-262 Lublin, prof. dr hab. Z. Targoński, mgr inż. E. Komoń-Janczara, mgr inż. A. Glibowska, Katedra Biotechnologii, Żywienia Człowieka i Towaroznawstwa Żywności, Wydz. Nauk o Żywności i Biotechnologii, Uniwersytet Przyrodniczy $w$ Lublinie, ul. Skromna 8, 20-704 Lublin. Kontakt: elwira.komon.janczara@up.lublin.pl 
producentów kwasu mlekowego warto koncentrować się na tych szczepach, które nie wytwarzają ww. produktów ubocznych. Zainteresowanie kwasem mlekowym zwiększa się w związku ze wzrastającym zapotrzebowaniem na kwas polimlekowy jako biodegradowalne tworzywo sztuczne, a także na liczne jego zastosowania w przemyśle spożywczym i farmaceutycznym. Światowa produkcja kwasu mlekowego wynosi obecnie ponad 150 tys. ton [3], a przewiduje się jej kilkukrotny wzrost do 2020 roku. Szczepy Rhizopus oryzae wytwarzają enancjomerycznie czysty kwas L(+) mlekowy, który jest preferowany w syntezie kwasu polimlekowego. Ponadto zaletą grzybowej produkcji kwasu mlekowego w porównaniu z bakteryjną fermentacją mlekową są małe wymagania pokarmowe i proste techniki oczyszczania kwasu mlekowego po fermentacji [2, 4].

Rhizopus oryzae wykorzystuje do produkcji kwasu mlekowego proste sacharydy, takie jak: glukoza, fruktoza, ksyloza i galaktoza, chociaż wydajność w przypadku tych dwóch ostatnich sacharydów nie jest duża [4]. Wybrane szczepy efektywnie fermentują disacharydy, takie jak sacharoza i maltoza, a także polisacharydy, takie jak skrobia $[7,11]$. Jako źródło azotu najczęściej wykorzystywane są jony amonowe lub azotanowe [12], a węglan wapniowy stosuje się jako środek neutralizujący powstający kwas mlekowy [8]. Wydajność kwasu mlekowego z sacharydów nie przekracza $85 \%$ przy produktywności nie większej niż $2 \mathrm{~g} / \mathrm{l} / \mathrm{h}$. Proces fermentacji można prowadzić zarówno metodą wgłębną, jak i w podłożu stałym. W tym drugim przypadku dużo niższe są koszty związane z napowietrzaniem i mieszaniem podłoża hodowlanego.

Celem pracy było pozyskanie nowych, wydajnych szczepów grzybów Rhizopus oryzae wytwarzających kwas $\mathrm{L}(+)$ mlekowy oraz porównanie ich ze szczepami ze znanych kolekcji zagranicznych.

\section{Material i metody badań}

\section{Mikroorganizmy}

Szczepy grzybów Rhizopus oryzae pochodziły z następujących kolekcji drobnoustrojów: DSMZ (German Collection of Microorganisms and Cell Collection - Brunszwik, Niemcy), NBRC (Biological Resource Center Culture Collection - Chiba, Japonia), Kolekcja Kultur Drobnoustrojów Przemysłowych Instytutu Biotechnologii Przemysłu Rolno-Spożywczego w Warszawie oraz Kolekcja Kultur Drobnoustrojów Katedry Biotechnologii, Żywienia Człowieka i Towaroznawstwa Żywności Uniwersytetu Przyrodniczego w Lublinie. Badaniom poddano 40 szczepów z rodzaju Rhizopus.

\section{Podłoża hodowlane $i$ warunki hodowli wytrzasanej}

Do hodowli grzybów Rhizopus oryzae stosowano podłoże o następującym skła-

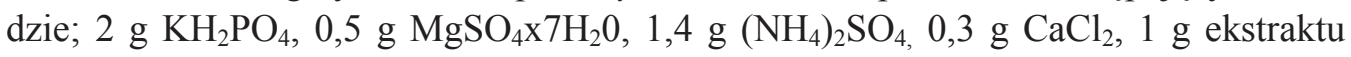
drożdżowego, $1 \mathrm{ml}$ Tween 80,50 lub $100 \mathrm{~g}$ sacharydu, $0,5 \mathrm{ml}$ roztworu mikroelementów $\left(5 \mathrm{~g} / \mathrm{dm}^{3} \mathrm{FeSO}_{4} \times 7 \mathrm{H}_{2} \mathrm{O}, 1,96 \mathrm{~g} / \mathrm{dm}^{3} \mathrm{MnSO}_{4} \times \mathrm{H}_{2} \mathrm{O}, 1,66 \mathrm{~g} / \mathrm{dm}^{3} \mathrm{ZnSO}_{4}\right)$, woda 
destylowana uzupełniająca pożywkę do $1 \mathrm{l}, \mathrm{pH}$ podłoża ustalano roztworami $0,1 \mathrm{M}$ $\mathrm{NaOH}$ oraz $1 \mathrm{M} \mathrm{HCl}$ na poziomie 5,5. Kolby Erlenmayera o pojemności $100 \mathrm{ml}$ napełniano $50 \mathrm{ml}$ pożywki, sterylizowano, a następnie szczepiono zawiesiną konidiów poszczególnych szczepów Rhizopus. Hodowle prowadzono na wytrząsarce rotacyjnej firmy Infors HT (Bottmingen, Szwajcaria) z zastosowaniem obrotów $200 \mathrm{rpm} / \mathrm{min}$ w temp. $32{ }^{\circ} \mathrm{C}$. Po $24 \mathrm{~h}$ do podłoża wprowadzano $1 \mathrm{~g}$ węglanu wapnia celem neutralizacji powstającego kwasu mlekowego.

Oznaczanie stężenia kwasu mlekowego i sacharydów w filtracie pohodowlanym

Płyn pohodowlany zalewano 7-procentowym kwasem siarkowym(VI) celem wytrącenia jonów wapniowych i usunięcia węglanu wapnia. Próbki ogrzewano do temp. $100{ }^{\circ} \mathrm{C}$ przez 10 min, a następnie chłodzono i dodawano acetonitryl w stosunku objętościowym $1: 1$. Zawiesinę wirowano przy $12000 \mathrm{x}$ g przez $15 \mathrm{~min}$, a następnie poddawano analizie HPLC. Oznaczanie stężenia sacharydów i kwasu mlekowego wykonywano przy użyciu chromatografu cieczowego firmy Gilson z detektorem UV-Vis oraz detektorem refraktometrycznym firmy Knauer (Berlin, Niemcy) do oznaczania stężenia sacharydów. Rozdział związków prowadzono przy użyciu kolumny Aminex HPX$87 \mathrm{H}$, stosując jako eluent $30 \mathrm{mM}$ roztwór kwasu siarkowego. Detekcję kwasów prowadzono przy długości fali $\lambda=210 \mathrm{~nm}$.

Określenie izomerów optycznych: kwasu D(-) i L(+) mlekowego

Określenie form izomerycznych kwasu mlekowego prowadzono według procedury dołączonej do testu enzymatycznego firmy R-Biopharm (Darmstadt, Niemcy) (kwas D-mlekowy/kwas L-mlekowy). Po zakończeniu 96-godzinnej hodowli wytrząsanej badanych szczepów rodzaju Rhizopus oryzae w podłożu z dodatkiem 50 g/1 glukozy próbki wirowano jak wyżej i badano na zawartość form kwasu mlekowego: $\mathrm{L}(+)$ i $\mathrm{D}(-)$. Formy izomeryczne kwasu określano jakościowo i ilościowo testem firmy R-Biopharm do enzymatycznego oznaczania kwasu D- i L-mlekowego. Pomiar spektrofotometryczny przygotowanych prób przeprowadzano przy użyciu spektrofotometru UV-Vis Unicam 5625 wyposażonego w lampę rtęciową (ATI Unicam, Boston, USA) przy długości fali $\lambda=365 \mathrm{~nm}$.

\section{Analiza statystyczna wyników}

Uzyskane wyniki poddano analizie statystycznej za pomocą programu Statistica 10.0 PL (StatSoft, Polska). Dla otrzymanych powtórzeń wyliczono średnią oraz odchylenia standardowe, a następnie wyznaczono przedziały ufności z zastosowaniem testu Tukeya. Do analiz przyjęto poziom istotności 0,05 . 


\section{Wyniki i dyskusja}

W tab. 1. przestawiono pochodzenie szczepów oraz wyniki z tych hodowli, w których w filtratach pohodowlanych stwierdzono obecność znaczących (przekraczających $30 \mathrm{~g} / 1)$ stężeń kwasu mlekowego.

Tabela 1. Wykaz szczepów Rhizopus oryzae wytwarzających kwas mlekowy w podłożu hodowlanym $\mathrm{z}$ dodatkiem glukozy w ilości $100 \mathrm{~g} / 1$

Table 1. List of Rhizopus oryzae strains producing lactic acid in a medium containing $100 \mathrm{~g} / \mathrm{l}$ of glucose

\begin{tabular}{|c|c|c|c|}
\hline $\begin{array}{l}\text { Szczep } \\
\text { Strain }\end{array}$ & $\begin{array}{l}\text { Gatunek } \\
\text { Species }\end{array}$ & $\begin{array}{l}\text { Źródło pochodzenia } \\
\text { Origin }\end{array}$ & $\begin{array}{l}\text { Stężenie kwasu mlekowego } \\
\text { The concentration of lactic } \\
\text { acid }[\mathrm{g} / \mathrm{l}])(\overline{\mathrm{x}} \pm \mathrm{s} / \mathrm{SD})\end{array}$ \\
\hline R-4 & Rhizopus oryzae & DSM 2200 & $43,91^{\mathrm{BC}} \pm 3,56$ \\
\hline $\mathrm{R}-16$ & Rhizopus oryzae & NBRC 4758 & $30,80^{\mathrm{A}} \pm 1,85$ \\
\hline $\mathrm{R}-36$ & Rhizopus oryzae & $\begin{array}{l}\text { wyizolowany z nasion zbóż } \\
\text { isolated from crop grains }\end{array}$ & $37,34^{\mathrm{AB}} \pm 1,81$ \\
\hline $\mathrm{R}-41$ & Rhizopus oryzae & wyizolowany z gleby / isolated from soil & $37,44^{\mathrm{AB}} \pm 1,80$ \\
\hline $\mathrm{R}-42$ & Rhizopus oryzae & wyizolowany z gleby / isolated from soil & $74,06^{\mathrm{G}} \pm 3,87$ \\
\hline $\mathrm{R}-43$ & Rhizopus oryzae & wyizolowany z gleby / isolated from soil & $70,44^{\mathrm{G}} \pm 1,58$ \\
\hline $\mathrm{R}-50$ & Rhizopus oryzae & IBPRS, Warszawa / IAFB Warsaw & $37,03^{\mathrm{AB}} \pm 3,67$ \\
\hline $\mathrm{R}-52$ & Rhizopus oryzae & IBPRS, Warszawa / IAFB Warsaw & $37,78^{\mathrm{B}} \pm 3,34$ \\
\hline $\mathrm{R}-72$ & Rhizopus oryzae & $\begin{array}{l}\text { wyizolowany z gleby (piaszczystej) } \\
\text { isolated from soil (sandy) }\end{array}$ & $54,02^{\mathrm{EF}} \pm 1,41$ \\
\hline $\mathrm{R}-73$ & Rhizopus oryzae & $\begin{array}{l}\text { wyizolowany z gleby (ziemi próchniczej) } \\
\text { isolated from soil (mould) }\end{array}$ & $55,28^{\mathrm{F}} \pm 1,18$ \\
\hline $\mathrm{R}-78$ & Rhizopus oryzae & DSM 854 & $51,60^{\mathrm{DEF}} \pm 2,06$ \\
\hline $\mathrm{R}-79$ & Rhizopus oryzae & DSM 906 & $48,56^{\mathrm{CDEF}} \pm 2,60$ \\
\hline $\mathrm{R}-82$ & Rhizopus oryzae & $\begin{array}{l}\text { wyizolowany z nasion zbóż } \\
\text { isolated from crop grains }\end{array}$ & $52,83^{\mathrm{DEF}} \pm 3,20$ \\
\hline $\mathrm{R}-83$ & Rhizopus oryzae & $\begin{array}{l}\text { wyizolowany z nasion zbóż } \\
\text { isolated from crop grains }\end{array}$ & $68,75^{\mathrm{G}} \pm 1,22$ \\
\hline $\mathrm{R}-84$ & Rhizopus oryzae & $\begin{array}{l}\text { wyizolowany z nasion zbóż } \\
\text { isolated from crop grains }\end{array}$ & $48,54^{\mathrm{CDEF}} \pm 1,40$ \\
\hline $\mathrm{R}-85$ & Rhizopus oryzae & $\begin{array}{l}\text { wyizolowany z nasion zbóż } \\
\text { isolated from crop grains }\end{array}$ & $47,13^{\mathrm{CDE}} \pm 0,69$ \\
\hline $\mathrm{R}-86$ & Rhizopus oryzae & $\begin{array}{l}\text { wyizolowany z nasion zbóż } \\
\text { isolated from crop grains }\end{array}$ & $47,35^{\mathrm{CDE}} \pm 0,87$ \\
\hline $\mathrm{R}-87$ & Rhizopus oryzae & $\begin{array}{l}\text { wyizolowany z nasion zbóż } \\
\text { isolated from crop grains }\end{array}$ & $44,70^{\mathrm{C}} \pm 1,15$ \\
\hline $\mathrm{R}-89$ & Rhizopus oryzae & $\begin{array}{l}\text { wyizolowany z nasion zbóż } \\
\text { isolated from crop grains }\end{array}$ & $46,42^{\mathrm{CD}} \pm 0,78$ \\
\hline $\mathrm{R}-90$ & Rhizopus oryzae & $\begin{array}{l}\text { wyizolowany z nasion zbóż } \\
\text { isolated from crop grains }\end{array}$ & $47,45^{\mathrm{CDE}} \pm 1,88$ \\
\hline
\end{tabular}

Objasnienia / Explanatory notes:

DSMZ - German Collection of Microorganism and Cell Cultures; NBRC - Biological Resource Center Culture Collection; IBPRS - Instytut Biotechnologii Przemysłu Rolno-Spożywczego w Warszawie / Institute of Agricultural and Food Biotechnology in Warsaw; Pozostałe szczepy były własnością Katedry 
Biotechnologii, Żywienia Człowieka i Towaroznawstwa Żywności Uniwersytetu Przyrodniczego w Lublinie / Other strains were owned by the Department of Biotechnology, Human Nutrition and Science of Food Commodities at the University of Life Sciences in Lublin; $\bar{x}$ - wartość średnia / mean value;

$\mathrm{s}$ - odchylenie standardowe / SD - standard deviation; Wyniki oznaczone tą samą literą nie różnią się statystycznie istotnie $(\mathrm{p}>0,05) /$ results denoted by the same letter do not differ statistically significantly $(\mathrm{p}>0.05) ; \mathrm{n}=3$.

Spośród badanych szczepów zdolność do wytwarzania znaczących ilości kwasu mlekowego wykazywały szczepy gatunku Rhizopus oryzae. Izolaty gatunku Rhizopus stolonifer (dane niepublikowane) nie wytwarzały natomiast kwasu mlekowego. Najwyższe stężenia kwasu mlekowego oznaczono w filtratach z izolatów Rhizopus oryzae oznaczonych jako R-42 i R-43 oraz nieznacznie niższe z izolatu oznaczonego jako R83, natomiast znacznie niższe wartości stężenia kwasu mlekowego stwierdzono po hodowli szczepów Rhizopus oryzae z kolekcji zachodnich DSM 2200, DSM 854, DSM 906 oraz NBRC 4758. Stężenia kwasu mlekowego w filtratach były bardzo zróżnicowane po hodowli badanych szczepów, co wskazuje na celowość prac selekcyjnych, by pozyskać jak najlepszych producentów kwasu mlekowego. Wstępna selekcja szczepów prowadzona była w podłożu zawierającym glukozę w ilości $100 \mathrm{~g} / \mathrm{l}$.

Do kolejnych badań wybrano 16 szczepów, aby ocenić ich zdolność do wykorzystania różnych monosacharydów w produkcji kwasu mlekowego (tab. 2).

Najwyższe stężenia kwasu mlekowego otrzymano po hodowli szczepów Rhizopus oryzae oznaczonych jako R-42 i R-43, gdy źródłem węgla była glukoza, nieznacznie niższe wartości otrzymano w przypadku mannozy i fruktozy, a dużo niższe, gdy źródłem węgla była ksyloza. Dla innych szczepów te relacje były odmienne. W przypadku kilku szczepów stężenie kwasu mlekowego w filtratach pohodowlanych było dwukrotnie wyższe, gdy w podłożu zastosowano ksylozę jako źródło węgla, w stosunku do szczepów R-42 i R-43 namnożonych na tym samym źródle węgla. Vially i wsp. [10] badali produkcję kwasu mlekowego w obecności różnych źródeł węgla przy użyciu szczepu Rhizopus oryzae UMIP 4.77 i stwierdzili najwyższe stężenie kwasu mlekowego w filtratach po hodowli badanego szczepu z dodatkiem glukozy jako źródła węgla, dużo niższe w obecności ksylozy lub sacharozy, a brak kwasu mlekowego w filtratach po hodowli z udziałem glicerolu lub laktozy. Badacze ci uzyskali wyższą produktywność kwasu mlekowego niż w przypadku badanych w niniejszej pracy szczepów, ale należy zaznaczyć, że hodowle prowadzili w warunkach kontrolowanego $\mathrm{pH}$ w bioreaktorze, co sprzyjało większej produktywności tego kwasu.

Najwyższą produktywność kwasu mlekowego osiągnięto, gdy źródłem węgla była glukoza, niezależnie od użytego szczepu Rhizopus oryzae (tab. 3). 
Tabela 2. Stężenie kwasu mlekowego uzyskane po 96-godzinnej hodowli wybranych szczepów Rhizopus oryzae w podłożu hodowlanym z dodatkiem monosacharydów w ilości $50 \mathrm{~g} / \mathrm{l}$

Table 2. Concentration of lactic acid obtained after $96 \mathrm{~h}$ cultivation of selected Rhizopus oryzae strains in medium containing $50 \mathrm{~g} / 1$ of monosaccharide

\begin{tabular}{|c|c|c|c|c|c|}
\hline \multirow{4}{*}{$\begin{array}{l}\text { Szczep } \\
\text { Strain }\end{array}$} & \multicolumn{5}{|c|}{$\begin{array}{c}\text { Średnie stężenie kwasu mlekowego } \\
\text { Average concentration of lactic acid [g/l] }\end{array}$} \\
\hline & \multicolumn{5}{|c|}{ Monosacharyd / Monosaccharide } \\
\hline & $\begin{array}{l}\text { Fruktoza } \\
\text { Fructose }\end{array}$ & $\begin{array}{l}\text { Galaktoza } \\
\text { Galactose }\end{array}$ & $\begin{array}{l}\text { Glukoza } \\
\text { Glucose }\end{array}$ & $\begin{array}{l}\text { Ksyloza } \\
\text { Xylose }\end{array}$ & $\begin{array}{l}\text { Mannoza } \\
\text { Mannose }\end{array}$ \\
\hline & \multicolumn{5}{|c|}{$\overline{\mathrm{x}} \pm \mathrm{s} / \mathrm{SD}$} \\
\hline $\mathrm{R}-4$ & $29,74^{\mathrm{CD}} \pm 1,15$ & $12,89^{\mathrm{b}} \pm 1,22$ & $38,85^{\text {C'D'E'F' }^{\prime} \pm 0,96}$ & $2,11^{\mathrm{b}^{\prime}} \pm 0,38$ & $7,69^{\mathrm{A}^{\prime \prime}} \pm 0,76$ \\
\hline $\mathrm{R}-16$ & $32,35^{\mathrm{DE}} \pm 1,32$ & $0,00^{\mathrm{a}} \pm 0,00$ & $36,45^{\mathrm{B}^{\prime} \mathrm{C}^{\prime} \mathrm{D}^{\prime}} \pm 1,63$ & $0,00^{\mathrm{a}^{\prime}} \pm 0,00$ & $12,56^{\mathrm{B} "} \pm 1,02$ \\
\hline $\mathrm{R}-42$ & $35,55^{\mathrm{EFG}} \pm 1,47$ & $22,01^{\mathrm{cd}} \pm 0,95$ & $44,69^{\mathrm{G}^{\prime}} \pm 1,12$ & $10,71^{\text {d'e' }^{\prime}} \pm 0,44$ & $36,68^{\mathrm{E}^{\prime}} \pm 1,39$ \\
\hline $\mathrm{R}-43$ & $36,33^{\mathrm{FGH}} \pm 1,19$ & $22,88^{\mathrm{d}} \pm 0,47$ & $43,07^{\mathrm{F}^{\prime} \mathrm{G}^{\prime}} \pm 1,58$ & $11,07^{\mathrm{e}^{\prime} \mathrm{f}^{\prime}} \pm 0,38$ & $41,04 \mathrm{l}^{\mathrm{F} "} \pm 1,00$ \\
\hline $\mathrm{R}-72$ & $36,52^{\mathrm{FGH}} \pm 0,88$ & $21,31^{\mathrm{cd}} \pm 0,52$ & $37,82^{\mathrm{C}^{\prime} \mathrm{D}^{\prime} \mathrm{E}^{\prime}} \pm 0,35$ & $10,57^{\mathrm{d}^{\prime} \mathrm{e}^{\prime}} \pm 0,37$ & $30,84^{\text {C'D" }} \pm 0,72$ \\
\hline $\mathrm{R}-73$ & $34,15^{\mathrm{EF}} \pm 0,41$ & $19,46^{\mathrm{c}} \pm 0,37$ & $37,70^{\mathrm{C}^{\prime} \mathrm{D}^{\prime} \mathrm{E}^{\prime}} \pm 0,72$ & $7,66^{\mathrm{c}^{\prime}} \pm 0,27$ & $30,48^{\text {C"D" }} \pm 0,42$ \\
\hline $\mathrm{R}-78$ & $39,16^{\mathrm{H}} \pm 1,00$ & $23,04^{\mathrm{de}} \pm 0,86$ & $43,79^{F^{\prime} G^{\prime}} \pm 1,40$ & $9,13^{\mathrm{c}^{\prime} \mathrm{d}^{\prime}} \pm 0,45$ & $30,77^{\text {C"D" }} \pm 0,83$ \\
\hline $\mathrm{R}-79$ & $38,05^{\mathrm{GH}} \pm 0,89$ & $21,23^{\mathrm{cd}} \pm 0,44$ & $41,93^{\mathrm{E}^{\prime} \mathrm{F}^{\prime} \mathrm{G}^{\prime}} \pm 1,40$ & $8,62^{\mathrm{c}^{\prime}} \pm 0,38$ & $28,90^{C "} \pm 0,66$ \\
\hline $\mathrm{R}-82$ & $24,39^{\mathrm{AB}} \pm 0,72$ & $31,70^{\mathrm{i}} \pm 1,02$ & $34,30^{\mathrm{A}^{\prime} \mathrm{B}^{\prime} \mathrm{C}^{\prime}} \pm 1,63$ & $12,55^{\mathrm{f}^{\prime}} \pm 0,54$ & $29,00^{\mathrm{C} "} \pm 0,86$ \\
\hline $\mathrm{R}-83$ & $27,01^{\mathrm{BC}} \pm 0,61$ & $29,85^{\mathrm{hi}} \pm 0,74$ & $41,25^{\text {D'E'F'G' }^{\prime}} \pm 1,64$ & $22,04^{\mathrm{i}^{\prime}} \pm 0,55$ & $28,42^{\mathrm{C} "} \pm 0,75$ \\
\hline $\mathrm{R}-84$ & $25,17^{\mathrm{AB}} \pm 0,68$ & $28,88^{\mathrm{ghi}} \pm 0,76$ & $36,77^{\mathrm{B}^{\prime} \mathrm{C}^{\prime} \mathrm{D}^{\prime}} \pm 1,27$ & $20,42^{\mathrm{h}^{\prime} \mathrm{i}^{\prime}} \pm 0,66$ & $31,75^{\text {C"D" }} \pm 0,81$ \\
\hline $\mathrm{R}-85$ & $24,48^{\mathrm{AB}} \pm 0,89$ & $26,95^{\mathrm{fgh}} \pm 0,96$ & $35,00^{\mathrm{A}^{\prime} \mathrm{B}^{\prime} \mathrm{C}^{\prime}} \pm 1,13$ & $21,10^{\mathrm{i}^{\prime}} \pm 0,75$ & $30,24^{\text {C'D" }} \pm 1,02$ \\
\hline $\mathrm{R}-86$ & $21,69^{\mathrm{A}} \pm 0,59$ & $25,87^{\mathrm{ef}} \pm 0,69$ & $36,97^{\mathrm{B}^{\prime} \mathrm{C}^{\prime} \mathrm{D}^{\prime} \mathrm{E}^{\prime}} \pm 1,09$ & $20,27^{\text {g'h'i' }} \pm 0,55$ & $33,49^{\mathrm{D} " \mathrm{E} "} \pm 0,79$ \\
\hline $\mathrm{R}-87$ & $25,21^{\mathrm{AB}} \pm 0,57$ & $26,53^{\mathrm{fg}} \pm 0,64$ & $31,17^{\mathrm{A}^{\prime}} \pm 1,12$ & $18,80^{\mathrm{g}^{\prime} \mathrm{h}^{\prime}} \pm 0,54$ & $30,08^{\text {C"D" }} \pm 0,66$ \\
\hline $\mathrm{R}-89$ & $23,47^{\mathrm{AB}} \pm 0,68$ & $24,05^{\mathrm{def}} \pm 0,68$ & $34,57^{\mathrm{A}^{\prime} \mathrm{B}^{\prime} \mathrm{C}^{\prime}} \pm 1,22$ & $20,98^{\mathrm{i}^{\prime}} \pm 0,52$ & $30,74^{C " D "} \pm 0,93$ \\
\hline $\mathrm{R}-90$ & $24,09^{\mathrm{AB}} \pm 0,55$ & $22,65^{\mathrm{d}} \pm 0,54$ & $32,28^{\mathrm{A}^{\prime} \mathrm{B}^{\prime}} \pm 1,16$ & $18,44^{\mathrm{g}^{\prime}} \pm 0,38$ & $33,03^{\mathrm{D}^{\prime \prime}} \pm 0,66$ \\
\hline
\end{tabular}

Objaśnienia / Explanatory notes:

Analizy statystyczne wykonano oddzielnie dla każdego monosacharydu / Statistical analyzes were performed separately for each monosaccharide; Pozostałe objaśnienia jak pod tab. 1. / Other explanatory notes as in Tab. 1.

Produktywność kwasu mlekowego na poziome bliskim $0,5 \mathrm{~g} / \mathrm{l} / \mathrm{h}$ należy uznać na tym etapie badań za korzystną. Najmniejszą produktywnością charakteryzowały się natomiast szczepy hodowane w podłożu z ksylozą. Zaobserwowano duże zróżnicowanie produktywności badanych szczepów. W podłożach z pozostałymi monosacharydami produktywność można jednak uznać za zadowalającą. 
Tabela 3. Produktywność kwasu mlekowego uzyskana po 96-godzinnej hodowli wybranych szczepów Rhizopus oryzae w podłożu hodowlanym z dodatkiem monosacharydów w ilości $50 \mathrm{~g} / 1$

Table 3. Lactic acid productivity after $96 \mathrm{~h}$ cultivation of selected Rhizopus oryzae strains obtained in medium containing $50 \mathrm{~g} / 1$ of monosaccharide

\begin{tabular}{|c|c|c|c|c|c|}
\hline \multirow{4}{*}{$\begin{array}{l}\text { Szczep } \\
\text { Strain }\end{array}$} & \multicolumn{5}{|c|}{$\begin{array}{c}\text { Produktywność kwasu mlekowego } \\
\text { Lactic acid productivity }[\mathrm{g} / \mathrm{l} / \mathrm{h}]\end{array}$} \\
\hline & \multicolumn{5}{|c|}{ Monosacharyd / Monosaccharide } \\
\hline & $\begin{array}{l}\text { Fruktoza } \\
\text { Fructose }\end{array}$ & $\begin{array}{l}\text { Galaktoza } \\
\text { Galactose }\end{array}$ & $\begin{array}{l}\text { Glukoza } \\
\text { Glucose }\end{array}$ & $\begin{array}{c}\text { Ksyloza } \\
\text { Xylose }\end{array}$ & $\begin{array}{l}\text { Mannoza } \\
\text { Mannose }\end{array}$ \\
\hline & \multicolumn{5}{|c|}{$\overline{\mathrm{x}} \pm \mathrm{s} / \mathrm{SD}$} \\
\hline $\mathrm{R}-4$ & $0,31^{\mathrm{CD}} \pm 0,01$ & $0,13^{\mathrm{b}} \pm 0,01$ & $0,40^{\mathrm{C}^{\prime} \mathrm{D} \mathrm{E}^{\prime} \mathrm{F}^{\prime}} \pm 0,01$ & $0,02^{\mathrm{b}^{\prime}} \pm 0,00$ & $0,08^{\mathrm{A}^{\prime \prime}} \pm 0,01$ \\
\hline $\mathrm{R}-16$ & $0,34^{\mathrm{DE}} \pm 0,01$ & $0,00^{\mathrm{a}} \pm 0,00$ & $0,38^{\mathrm{B}^{\prime} \mathrm{C}^{\prime} \mathrm{D}} \pm 0,02$ & $0,00^{\mathrm{a}^{\prime}} \pm 0,00$ & $0,13^{\mathrm{B} "} \pm 0,01$ \\
\hline R-42 & $0,37^{\mathrm{EFG}} \pm 0,02$ & $0,23^{\text {cd }} \pm 0,01$ & $0,47^{\mathrm{G}^{\prime}} \pm 0,01$ & $0,11^{\text {d'e }^{\prime} \mathrm{f}^{\prime}} \pm 0,00$ & $0,38^{\mathrm{E} "} \pm 0,01$ \\
\hline $\mathrm{R}-43$ & $0,38^{\mathrm{FGH}} \pm 0,01$ & $0,24^{\mathrm{d}} \pm 0,00$ & $0,45^{\mathrm{F}^{\prime} \mathrm{G}^{\prime}} \pm 0,02$ & $0,12^{\mathrm{e}^{\prime \mathrm{f}^{\prime}}} \pm 0,00$ & $0,43^{\mathrm{F} "} \pm 0,01$ \\
\hline $\mathrm{R}-72$ & $0,38^{\mathrm{FGH}} \pm 0,01$ & $0,22^{\mathrm{cd}} \pm 0,01$ & $0,39^{\mathrm{C}^{\prime} \mathrm{D}^{\prime} \mathrm{E}^{\prime}} \pm 0,00$ & $0,11^{\text {d'e' }} \pm 0,00$ & $0,32^{\text {C"D" }} \pm 0,01$ \\
\hline $\mathrm{R}-73$ & $0,36^{\mathrm{EF}} \pm 0,00$ & $0,20^{\mathrm{c}} \pm 0,00$ & $0,39^{C^{\prime} D^{\prime} E^{\prime}} \pm 0,01$ & $0,08^{\mathrm{c}^{\prime}} \pm 0,00$ & $0,32^{\text {C"N" }} \pm 0,00$ \\
\hline $\mathrm{R}-78$ & $0,41^{\mathrm{H}} \pm 0,01$ & $0,24^{\mathrm{de}} \pm 0,01$ & $0,46^{\mathrm{F}^{\prime} \mathrm{G}^{\prime}} \pm 0,01$ & $0,10^{\mathrm{c}^{\prime} \mathrm{d}^{\prime}} \pm 0,00$ & $0,32^{\text {C"N" }} \pm 0,01$ \\
\hline R-79 & $0,40^{\mathrm{GH}} \pm 0,01$ & $0,22^{\text {cd }} \pm 0,00$ & $0,44^{\mathrm{E}^{\prime} \mathrm{F}^{\prime} \mathrm{G}^{\prime}} \pm 0,01$ & $0,09^{c^{\prime}} \pm 0,00$ & $0,30^{\mathrm{C} "} \pm 0,01$ \\
\hline $\mathrm{R}-82$ & $0,25^{\mathrm{AB}} \pm 0,01$ & $0,33^{\mathrm{i}} \pm 0,01$ & $0,36^{\mathrm{A}^{\prime} \mathrm{B}^{\prime} \mathrm{C}^{\prime}} \pm 0,02$ & $0,13^{\mathrm{f}^{\prime}} \pm 0,01$ & $0,30^{\mathrm{C} "} \pm 0,01$ \\
\hline $\mathrm{R}-83$ & $0,28^{\mathrm{BC}} \pm 0,01$ & $0,31^{\mathrm{hi}} \pm 0,01$ & $0,43^{\text {D'E'F'G' }^{\prime} \pm 0,02}$ & $0,23^{\mathrm{i}^{\prime}} \pm 0,01$ & $0,30^{\mathrm{C} "} \pm 0,01$ \\
\hline R-84 & $0,26^{\mathrm{AB}} \pm 0,01$ & $0,30^{\text {ghi }} \pm 0,01$ & $0,38^{\mathrm{B}^{\prime} \mathrm{C}^{\prime} \mathrm{D}^{\prime}} \pm 0,01$ & $0,21^{\mathrm{h}^{\prime} \mathrm{i}^{\prime}} \pm 0,01$ & $0,33^{\text {C'D" }} \pm 0,01$ \\
\hline $\mathrm{R}-85$ & $0,26^{\mathrm{AB}} \pm 0,01$ & $0,28^{\text {fgh }} \pm 0,01$ & $0,36^{\mathrm{A}^{\prime} \mathrm{B}^{\prime} \mathrm{C}^{\prime}} \pm 0,01$ & $0,22^{i^{\prime}} \pm 0,01$ & $0,32^{\text {C"'D" }} \pm 0,01$ \\
\hline $\mathrm{R}-86$ & $0,23^{\mathrm{A}} \pm 0,01$ & $0,27^{\mathrm{ef}} \pm 0,01$ & $0,39^{\mathrm{B}^{\prime} \mathrm{C}^{\prime} \mathrm{D}^{\prime} \mathrm{E}^{\prime}} \pm 0,01$ & $0,21^{\text {g'h'i' }} \pm 0,01$ & $0,35^{\text {D"E }} \pm 0,01$ \\
\hline $\mathrm{R}-87$ & $0,26^{\mathrm{AB}} \pm 0,01$ & $0,28^{\mathrm{fg}} \pm 0,01$ & $0,32^{\mathrm{A}^{\prime}} \pm 0,01$ & $0,20^{\mathrm{g}^{\prime} \mathrm{h}^{\prime}} \pm 0,01$ & $0,31^{\text {C"D" }} \pm 0,01$ \\
\hline R-89 & $0,24^{\mathrm{AB}} \pm 0,01$ & $0,25^{\mathrm{def}} \pm 0,01$ & $0,36^{\mathrm{A}^{\prime} \mathrm{B}^{\prime} \mathrm{C}^{\prime}} \pm 0,01$ & $0,22^{i^{\prime}} \pm 0,01$ & $0,32^{\text {C"D" }} \pm 0,01$ \\
\hline R-90 & $0,25^{\mathrm{AB}} \pm 0,01$ & $0,24^{\mathrm{d}} \pm 0,01$ & $0,34^{\mathrm{A}^{\prime} \mathrm{B}^{\prime}} \pm 0,01$ & $0,19^{g^{\prime}} \pm 0,00$ & $0,34^{\mathrm{D}^{\prime \prime}} \pm 0,01$ \\
\hline
\end{tabular}

Objaśnienia jak pod tab. 2. / Explanatory notes as in Tab. 2.

Ze względów aplikacyjnych ważnymi źródłami węgla są sacharoza i skrobia, które należą do podstawowych źródeł węgla i energii w procesach biotechnologicznych, a jednocześnie mają istotny wpływ na cenę produktu końcowego. W tab. 4. przedstawiono wyniki stężeń kwasu mlekowego w filtratach po hodowlach badanych szczepów Rhizopus oryzae w podłożu z sacharozą lub skrobią. Spośród 16 szczepów w podłożu z sacharozą tylko 6 wytwarzało kwas mlekowy, a najwyższe stężenia kwasu stwierdzono w filtratach po hodowli szczepów oznaczonych jako R-83 i R-84. Zadowalająca była także produktywność tych szczepów, nawet nieznacznie większa niż po hodowli w podłożach z glukozą (tab. 3). Szczepy, które wyróżniały się dużą produkcją kwasu mlekowego w podłożu z glukozą, a które były opisane wcześniej, tj. R-42 i R-43, nie były natomiast zdolne do produkcji kwasu mlekowego w podłożu z dodatkiem sacharozy. Watanabe i Oda [11] przebadali 26 szczepów Rhizopus oryzae z kolekcji NBRC i stwierdzili, że tylko 2 z nich wytwarzały kwas mlekowy w podłożu z sacharozą, 
w tym szczep $R$. oryzae NBRC 4785 . W niniejszej pracy także stwierdzono, że ten szczep wytwarza kwas mlekowy w podłożu z sacharozą, jednak zarówno stężenie kwasu, jak i wydajność po 4-dobowej hodowli były wielokrotnie mniejsze niż w przypadku szczepu $R$. oryzae R-83 z kolekcji Katedry. Ponadto warto zwrócić uwagę, że wielokrotnie omawiany w publikacjach szczep Rhizopus oryzae NRRL 395 zdaniem Bulut i wsp. [1] był zdolny do produkcji kwasu mlekowego z sacharozy, ale ze stosunkowo małą wydajnością wynoszącą $0,42 \mathrm{~g} / \mathrm{g}$, gdy stężenie sacharozy w podłożu wynosiło $50 \mathrm{~g} / \mathrm{l}$. Dlatego podejmowanie prac nad selekcją szczepów efektywnie metabolizujących czystą sacharozę, jak również melasę do kwasu mlekowego jest w pełni uzasadnione. Guo i wsp. [3] wyselekcjonowali szczep Rhizopus oryzae GY18, który pozwalał uzyskać w filtracie pohodowlanym ilość kwasu mlekowego równą 97,5 g/1, gdy w podłożu było $120 \mathrm{~g}$ sacharozy.

Tabela 4. Stężenia i produktywności kwasu mlekowego uzyskane po 96-godzinnej hodowli wybranych szczepów Rhizopus oryzae w podłożu z dodatkiem sacharydów w ilości 50 g/l

Table 4. Lactic acid concentrations and productivity after $96 \mathrm{~h}$ cultivation of selected Rhizopus oryzae strains obtained in medium containing $50 \mathrm{~g} / \mathrm{l}$ of monosaccharide

\begin{tabular}{|c|c|c|c|c|}
\hline \multirow{6}{*}{$\begin{array}{c}\text { Szczep } \\
\text { Strain }\end{array}$} & \multicolumn{4}{|c|}{ Sacharyd / Saccharide } \\
\hline & \multicolumn{2}{|c|}{ Sacharoza / Sucrose } & \multicolumn{2}{|c|}{ Skrobia / Starch } \\
\hline & Stężenie kwasu & Produktywność & Stężenie kwasu & Produktywność \\
\hline & Lactic acid con- & $\begin{array}{l}\text { Kwasu miekowego } \\
\text { Lactic acid produc- }\end{array}$ & Lactic acid con- & $\begin{array}{l}\text { Kwasu mekowego } \\
\text { Lactic acid produc- }\end{array}$ \\
\hline & centration $[\mathrm{g} / \mathrm{l}]$ & tivity $[\mathrm{g} / \mathrm{l} / \mathrm{h}]$ & centration $[\mathrm{g} / \mathrm{l}]$ & tivity $[\mathrm{g} / \mathrm{l} / \mathrm{h}]$ \\
\hline & \multicolumn{4}{|c|}{$\overline{\mathrm{x}} \pm \mathrm{s} / \mathrm{SD}$} \\
\hline $\mathrm{R}-4$ & $0,00^{A} \pm 0,00$ & $0,00^{A} \pm 0,00$ & $3,79^{\mathrm{a}} \pm 0,47$ & $0,04^{\mathrm{a}} \pm 0,00$ \\
\hline R-16 & $0,86^{\mathrm{A}} \pm 0,16$ & $0,01^{\mathrm{A}} \pm 0,00$ & $8,83^{b} \pm 0,66$ & $0,09^{\mathrm{b}} \pm 0,01$ \\
\hline $\mathrm{R}-42$ & $0,00^{A} \pm 0,00$ & $0,00^{A} \pm 0,00$ & $19,88^{\mathrm{cd}} \pm 0,69$ & $0,21^{\mathrm{cd}} \pm 0,01$ \\
\hline R-43 & $0,00^{A} \pm 0,00$ & $0,00^{A} \pm 0,00$ & $18,49^{\mathrm{c}} \pm 0,54$ & $0,19^{\mathrm{c}} \pm 0,01$ \\
\hline $\mathrm{R}-72$ & $28,40^{\mathrm{B}} \pm 0,40$ & $0,30^{B} \pm 0,00$ & $8,22^{b} \pm 0,38$ & $0,09^{\mathrm{b}} \pm 0,00$ \\
\hline $\mathrm{R}-73$ & $0,00^{A} \pm 0,00$ & $0,00^{A} \pm 0,00$ & $8,63^{b} \pm 0,28$ & $0,09^{b} \pm 0,00$ \\
\hline $\mathrm{R}-78$ & $0,00^{A} \pm 0,00$ & $0,00^{A} \pm 0,00$ & $9,21^{b} \pm 0,44$ & $0,10^{\mathrm{b}} \pm 0,00$ \\
\hline $\mathrm{R}-79$ & $0,00^{A} \pm 0,00$ & $0,00^{A} \pm 0,00$ & $7,73^{\mathrm{b}} \pm 0,31$ & $0,08^{\mathrm{b}} \pm 0,00$ \\
\hline $\mathrm{R}-82$ & $0,00^{A} \pm 0,00$ & $0,00^{A} \pm 0,00$ & $22,96^{\mathrm{ef}} \pm 0,65$ & $0,24^{\mathrm{ef}} \pm 0,01$ \\
\hline $\mathrm{R}-83$ & $44,95^{\mathrm{E}} \pm 0,56$ & $0,47^{\mathrm{E}} \pm 0,01$ & $25,44^{\mathrm{fg}} \pm 0,68$ & $0,27^{\mathrm{fg}} \pm 0,01$ \\
\hline R-84 & $41,79^{D} \pm 1,15$ & $0,44^{\mathrm{D}} \pm 0,01$ & $26,81^{\mathrm{gh}} \pm 0,74$ & $0,28^{\mathrm{gh}} \pm 0,01$ \\
\hline $\mathrm{R}-85$ & $0,00^{A} \pm 0,00$ & $0,00^{A} \pm 0,00$ & $28,25^{\mathrm{h}} \pm 0,91$ & $0,29^{\mathrm{h}} \pm 0,01$ \\
\hline R-86 & $0,00^{A} \pm 0,00$ & $0,00^{\mathrm{A}} \pm 0,00$ & $27,27^{\mathrm{gh}} \pm 0,61$ & $0,28^{\mathrm{gh}} \pm 0,01$ \\
\hline $\mathrm{R}-87$ & $38,28^{C} \pm 1,02$ & $0,40^{C} \pm 0,01$ & $22,20^{\mathrm{de}} \pm 0,61$ & $0,23^{\mathrm{de}} \pm 0,01$ \\
\hline $\mathrm{R}-89$ & $38,70^{C} \pm 0,93$ & $0,40^{C} \pm 0,01$ & $33,67^{i} \pm 1,05$ & $0,35^{i} \pm 0,01$ \\
\hline R-90 & $0,00^{A} \pm 0,00$ & $0,00^{A} \pm 0,00$ & $18,44^{\mathrm{c}} \pm 0,61$ & $0,19^{\mathrm{c}} \pm 0,00$ \\
\hline
\end{tabular}

Objaśnienia / Explanatory notes:

Analizy statystyczne wykonano oddzielnie dla sacharozy i skrobi / Statistical analyzes were performed separately for sucrose and starch; Pozostałe objaśnienia jak pod tab. 1. / Other explanatory notes as in Tab. 1. 
Tabela 5. Stężenia kwasu mlekowego formy L-(+) i D-(-) uzyskane po hodowli szczepów Rhizopus oryzae w podłożu z dodatkiem glukozy w ilości $50 \mathrm{~g} / 1$

Table 5. Concentrations of lactic acid of $\mathrm{L}(+)$ and $\mathrm{D}(-)$ form obtained after cultivation of Rhizopus oryzae strains in medium containing $50 \mathrm{~g} / \mathrm{l}$ of glucose

\begin{tabular}{|c|c|c|c|}
\hline \multirow[t]{2}{*}{$\begin{array}{l}\text { Szczep } \\
\text { Strain }\end{array}$} & $\begin{array}{l}\text { Stężenie kwasu mle- } \\
\text { kowego formy } \mathrm{L}(+) \\
\text { Lactic acid } \mathrm{L}(+) \text { form } \\
\text { concentration } \\
{[\mathrm{g} / \mathrm{l}]}\end{array}$ & $\begin{array}{c}\text { Stężenie kwasu mle- } \\
\text { kowego formy } \\
\mathrm{D}(-) \\
\text { Lactic acid } \mathrm{D}(-) \text { form } \\
\text { concentration } \\
{[\mathrm{g} / \mathrm{l}]}\end{array}$ & $\begin{array}{c}\text { Stężenie kwasu } \\
\text { mlekowego ogółem } \\
\text { Summary of lactic acid } \\
\text { concentration } \\
{[\mathrm{g} / \mathrm{l}]}\end{array}$ \\
\hline & \multicolumn{3}{|c|}{$\overline{\mathrm{x}} \pm \mathrm{s} / \mathrm{SD}$} \\
\hline $\mathrm{R}-4$ & $36,84^{\mathrm{BCDE}} \pm 0,75$ & $0,0002^{\mathrm{ab}} \pm 0,00001$ & $36,84^{\mathrm{B}^{\prime} \mathrm{CDE}} \pm 0,57$ \\
\hline R-16 & $35,09^{\mathrm{BCD}} \pm 0,42$ & $0,0036^{\mathrm{de}} \pm 0,004$ & $35,09^{\mathrm{BCD}} \pm 085$ \\
\hline $\mathrm{R}-42$ & $43,58^{\mathrm{F}} \pm 1,06$ & $0,00^{\mathrm{a}} \pm 0,00$ & $43,58^{\mathrm{F}} \pm 1,67$ \\
\hline $\mathrm{R}-43$ & $41,94^{\mathrm{EF}} \pm 0,98$ & $0,00^{\mathrm{a}} \pm 0,00$ & $41,94^{\mathrm{EF}} \pm 1,05$ \\
\hline $\mathrm{R}-72$ & $34,12^{\mathrm{ABC}} \pm 0,24$ & $0,0013^{\mathrm{c}} \pm 0,0001$ & $34,13^{\mathrm{ABC}} \pm 0,79$ \\
\hline $\mathrm{R}-73$ & $35,60^{\mathrm{ABC}} \pm 0,74$ & $0,0039^{\mathrm{e}} \pm 0,006$ & $35,60^{\mathrm{BCD}} \pm 1,45$ \\
\hline $\mathrm{R}-78$ & $43,25^{\mathrm{F}} \pm 0,83$ & $0,00^{\mathrm{a}} \pm 0,00$ & $43,25^{\mathrm{F}} \pm 0,73$ \\
\hline R-79 & $40,06^{\mathrm{DEF}} \pm 0,53$ & $0,0014^{\mathrm{c}} \pm 0,0003$ & $40,07^{\mathrm{DEF}} \pm 0,66$ \\
\hline $\mathrm{R}-82$ & $35,01^{\mathrm{ABCD}} \pm 0,12$ & $0,0006^{\mathrm{b}} \pm 0,0001$ & $35,01^{\mathrm{ABCD}} \pm 0,94$ \\
\hline $\mathrm{R}-83$ & $39,53^{\mathrm{CDEF}} \pm 0,60$ & $0,0006^{\mathrm{b}} \pm 0,0001$ & $39,54^{\mathrm{CDEF}} \pm 1,12$ \\
\hline $\mathrm{R}-84$ & $37,21^{\mathrm{BCDE}} \pm 0,71$ & $0,00^{\mathrm{a}} \pm 0,00$ & $37,21^{\mathrm{BCDE}} \pm 0,33$ \\
\hline $\mathrm{R}-85$ & $35,99^{\mathrm{BCD}} \pm 0,86$ & $0,00^{\mathrm{a}} \pm 0,00$ & $35,99^{\mathrm{BCD}} \pm 0,47$ \\
\hline $\mathrm{R}-86$ & $33,61^{\mathrm{AB}} \pm 0,36$ & $0,0032^{\mathrm{d}} \pm 0,0002$ & $33,62^{\mathrm{AB}} \pm 0,55$ \\
\hline $\mathrm{R}-87$ & $32,01^{\mathrm{AB}} \pm 1,16$ & $0,00^{\mathrm{a}} \pm 0,00$ & $32,01^{\mathrm{AB}} \pm 1,19$ \\
\hline $\mathrm{R}-89$ & $35,34^{\mathrm{BCD}} \pm 1,26$ & $0,0004^{\mathrm{ab}} \pm 0,0001$ & $35,34^{\mathrm{BCD}} \pm 0,46$ \\
\hline R-90 & $29,37^{\mathrm{A}} \pm 0,93$ & $0,00^{\mathrm{a}} \pm 0,00$ & $29,37^{\mathrm{A}} \pm 1,45$ \\
\hline
\end{tabular}

Objaśnienia / Explanatory notes:

Analizy statystyczne wykonano oddzielnie dla formy L(+), D(-) i ogólnego stężenia kwasu mlekowego / Statistical analyzes were performed separately for $\mathrm{L}(+)$ and $\mathrm{D}(-)$ forms and for total concentrations of lactic acid; Pozostałe objaśnienia jak pod tab. 1. / Other explanatory notes as in Tab. 1.

Wszystkie szczepy testowane w ramach niniejszej pracy były zdolne do produkcji kwasu mlekowego w podłożu ze skrobią, jednak oznaczone stężenia kwasu mlekowego w filtratach pohodowlanych były znacznie niższe niż po hodowlach na podłożach z glukozą czy mannozą. Również wartości produktywności kwasu mlekowego uzyskane przez badane szczepy Rizopus oryzae w podłożu ze skrobią były znacznie mniejsze niż w przypadku użycia jako źródła węgla pozostałych monosacharydów (z wyjątkiem ksylozy). Zhan i wsp. [12] uzyskali większą wydajności procesu produkcji kwasu mlekowego, dochodzącą do $90 \%$, gdy w podłożu jako źródła węgla użyto skrobi, ale wartości te otrzymano po wstępnej optymalizacji warunków hodowli, w szczególności po dodatku optymalnego stężenia azotu. We wstępnych badaniach własnych najlepszy 
szczep R-89 wytwarzał kwas mlekowy z wydajnością ok. 70 \% ze skrobi jako źródła węgla, co należy uznać za wynik satysfakcjonujący na tym etapie badań.

Wszystkie badane szczepy zamieszczone w tab. 5. wytwarzały formę $\mathrm{L}(+)$ kwasu mlekowego z blisko 100-procentową czystością, co jest bardzo istotne w dalszym wykorzystaniu kwasu zarówno jako dodatku do żywności, w farmacji, a także w produkcji tworzyw sztucznych.

\section{Wnioski}

1. W wyniku selekcji szczepów z rodzaju Rhizopus uzyskano 2 szczepy Rhizopus oryzae R-42 i R-43, które wytwarzały kwas L (+) mlekowy z wydajnością ponad 80-procentową z glukozy i z nieznacznie mniejszą wydajnością, gdy źródłem węgla była mannoza, fruktoza i galaktoza.

2. Wyselekcjonowane szczepy były zdolne do bezpośredniej konwersji skrobi do kwasu mlekowego, przy czym wydajność była uzależniona od szczepu użytego do fermentacji.

3. Tylko 5 szczepów było zdolnych do wzrostu i produkcji kwasu mlekowego w podłożu z sacharozą. Największą wydajność procesu produkcji kwasu mlekowego wynoszącą $0,82 \mathrm{~g} / \mathrm{g}$ uzyskano podczas fermentacji sacharozy przez szczep Rhizopus oryzae R-83.

4. Dalsze prace, $w$ tym optymalizacja hodowli w bioreaktorach, powinny przyczynić się w pierwszym rzędzie do zwiększenia wydajności procesu produkcji kwasu mlekowego, która już na wstępnym etapie badań jest obiecująca.

5. Badane szczepy w blisko $100 \%$ wytwarzały kwas L(+) mlekowy, co jest ważne w jego późniejszych aplikacjach.

\section{Literatura}

[1] Bulut S., Elibol M., Ozer D.: Effect of different carbon sources on L(+) lactic acid production by Rhizopus oryzae. Biochem. Bioeng. J., 2004, 21, 33-37.

[2] Ghaffar T., Irshad M., Anwar Z., Aqil T., Zulfiqar Z., Rig A., Kamran M., Ehsan N.: Recent trends in lactic acid biotechnology: A brief review on production to purification. J. Radiat. Res. Appl. Sci., 2014, 7, 222-229.

[3] Guo Y., Yan Q., Jiang Zh., Teng Ch., Wang X.: Efficient production of lactic acid from sucrose and corncob hydrolizates by a newly Rhizopus oryzae GY18. J. Ind. Microbiol. Biotechnol., 2010, 37, 1137-1143.

[4] John R.P., Anisha G.S., Nampoothiri K.M., Pandey A.: Direct lactic acid fermentation: Focus on simultaneous saccharification and lactic acid production. Biotechnol. Adv., 2009, 27, 145-152.

[5] Meussen B.J., de Graaff L.H., Sanders J.P.M., Weusthuis R.A.: Metabolic engineering of Rhizopus oryzae for production of platform chemicals. Appl. Microbiol. Biotechnol., 2012, 94, 875-886.

[6] Oda Y., Saito K., Yamauchi H., Mori M.: Lactic acid fermentation of potato pulp by the fungus Rhizopus oryzae. Current Microbiol., 2002, 45, 1-4.

[7] Pałys M., Targoński Z.: Produkcja kwasu mlekowego przez grzyby z rodzaju Rhizopus. Żywność. Nauka. Technologia. Jakość, 2013, 4 (89), 21-36. 
[8] Soccol C.R., Stonoga V.I., Raimbault M.: Production of L-lactic acid by Rhizopus species. World J. Microbiol. Biotechnol., 1994, 10, 433-435.

[9] Thitipraset S., Songserm P., Boonkong W., Sooksai S., Kodama K., Thongchul N.: Manipulating pyruvate decarboxylase by addition of enzyme regulations during fermentation of Rhizopus oryzae to enhance lactic acid production. Appl. Biochem. Biotechnol., 2014, 174, 1795-1809.

[10] Vially G., Marchal R., Guilbert N.: L(+) Lactate production from carbohydrates and lignocellulosic materials by Rhizopus oryzae UMIP 4.77. World J. Microbiol. Biotechnol., 2010, 26, 607-614.

[11] Watanabe T., Oda Y.: Comparison of sucrose-hydrolyzing enzyme produced by Rhizopus oryzae and Amylomyces rouxii. Biosci. Biotechnol. Biochem., 2008, 72 (12), 3167-3173.

[12] Zhan Z.Y., Jin B., Kelly J.M.: Production of lactic acid and byproducts from waste potato starch by Rhizopus arrhizus: Role of nitrogen sources. World J. Microbiol. Biotechnol., 2007, 23, 229-236.

\section{SELECTING NEWLY ISOLATED RHIZOPUS ORYZAE STRAINS FOR EFFICIENT PRODUCTION OF L(+) LACTIC ACID}

\section{S u m m a r y}

The objective of the research study was to assess the ability of newly isolated Rhizopus oryzae strains to produce $\mathrm{L}(+)$ lactic acid. 40 isolates were tested and a significant lactic acid concentration was found in the post-culture filtrates of 20 isolates. Those strains were assigned to the Rhizopus oryzae species, whereas the rest of the strains, including species belonging to the Rhizopus stolonifer species, did not show these abilities. The lactic acid concentration levels in the filtrates varied depending on the used strain of the fungus and the type of carbon source. The highest lactic acid concentration, $74.06 \mathrm{~g} / \mathrm{L}$, was determined in a post-culture filtrate of R-42 Rhizopus oryzae strain, in a medium containing $100 \mathrm{~g} / \mathrm{L}$ of glucose. The highest yield of lactic acid, $89.4 \%$, and a productivity close to $0.5 \mathrm{~g} / \mathrm{Lxh}$ were also obtained after cultivation of R-42 R. oryzae strain in a medium containing $50 \mathrm{~g} / \mathrm{L}$ of glucose. Slightly lower values were reported when mannose or fructose were used as a carbon source. Yet, significantly lower values were obtained when the carbon source was a xylose or a starch. Of all the strains tested only 5 were able to grow and produce lactic acid in a medium with sucrose. The best R- $83 R$. oryzae strain was characterized by a high yield production of lactic acid amounting to nearly $90 \%$ in a medium supplemented with $50 \mathrm{~g} / \mathrm{L}$ of sucrose. All the tested strains produced $\mathrm{L}(+)$ lactic acid.

Key words: Rhizopus oryzae, L(+) lactic acid, fermentation, saccharides 